\title{
Емкостная спектроскопия дырочных ловушек в высокоомных структурах арсенида галлия, выращенных жидкофазным методом
}

\author{
(ㄱ А.В. Мурель ${ }^{1}$, В.Б. Шмагин ${ }^{1}$, В.Л. Крюков ${ }^{2}$, С.С. Стрельченко ${ }^{2}$, Е.А. Суровегина ${ }^{\Uparrow}$, В.И. Шашкин ${ }^{1}$ \\ ${ }^{1}$ Институт фризики микроструктур Российской академии наук, \\ 603087 Нижний Новгород, Россия \\ ${ }^{2} \mathrm{OOO} \mathrm{„МеГа} \mathrm{Эпитех“,}$ \\ 248033 Калуга, Россия \\ I E-mail: suroveginaka@ipmras.ru
}

(Получена 27 марта 2017 г. Принята к печати 12 мая 2017 г.)

B выращенных методом жидкофазной эпитаксии GaAs-структурах с дырочным типом проводимости методами емкостной спектроскопии (адмиттанс-спектроскопии и нестационарной емкостной спектроскопии глубоких уровней) обнаружены три глубоких акцепторных уровня с энергиями активации $\sim 0.7, \sim 0.41$ и $\sim 0.16$ эВ. Первые два уровня известны как $H L 2, H L 5$ и связываются с особенностями роста слоев GaAs методом жидкофазной эпитаксии. Они являются эффективными рекомбинационными центрами, определяющими обратные токи в $p-i-n$-диодах, что подтверждается изучением температурных зависимостей обратных токов. Уровень с энергией $E_{v}+0.16$ эВ может быть связан с двухзарядным акцепторным уровнем собственного антиструктурного дефекта $\mathrm{Ga}_{\mathrm{As}}$, который в однозарядном состоянии определяет уровень легирования структур.

DOI: $10.21883 /$ FTP.2017.11.45107.21

\section{1. Введение}

Одним из направлений развития компонентной базы силовой электроники является разработка высоковольтных быстродействующих переключающих диодов на основе многослойных эпитаксиальных GaAs$p-i-n$-структур, изготовленных методом жидкофазной эпитаксии (ЖФЭ) [1]. Особенностью данной технологии является совместное легирование выращиваемых слоев атомами кремния и кислорода, что позволяет в одном эпитаксиальном слое сформировать $p-i-n$-структуру с протяженной высокоомной областью. Силовые диоды, изготовленные на основе GaAs $p-i-n$-структур, выращенных методом ЖФЭ, обладают рядом существенных достоинств: малое время обратного восстановления, рабочая температура до $250^{\circ} \mathrm{C}$, высокая радиационная стойкость [1].

Установлено, что в процессе ЖФЭ, в отличие от газофазной и молекулярно-лучевой эпитаксии, атомы кремния и кислорода, а также комплексы на их основе образуют в запрещенной зоне арсенида галлия „неклассические“ глубокие уровни (ГУ) с большой энергией ионизации, которые оказывают значительное влияние на переходные характеристики арсенид-галлиевых диодов (время жизни неравновесных носителей заряда и время нарастания напряжения) [2]. Дефекты и интерфейсные состояния, образующиеся в процессе эпитаксиального роста на $p-i-n$-структур GaAs, интенсивно изучались [3-7], и было показано, что при выращивании эпитаксиальных слоев GaAs методом ЖФЭ из ограниченного объема раствора-расплава при низкой температуре начала кристаллизации, $T_{b}=650-800^{\circ} \mathrm{C}$, в слоях GaAs преимущественно формируются дефекты с ГУ: $H L 2\left(E_{v}+0.72\right.$ эВ) и $H L 5\left(E_{v}+0.42\right.$ эВ $)$.
Отметим, что вышеприведенные исследования проводились на биполярных $p-i-n$-структурах, где наличие двух переходов (интерфейсов) затрудняет интерпретацию данных, получаемых методами емкостной спектроскопии. В данной работе приведены результаты исследований изотипных структур $p-p^{+}$и $n-n^{+}$с контактом Шоттки.

\section{2. Эксперимент}

Исследуемые в данной работе $n-n^{+}-$и $p-p^{+}$-структуры на основе GaAs выращивались методом ЖФЭ на сильно легированных подложках $\mathrm{GaAs} n$ - и $p$-типа проводимости соответственно. Жидкофазная эпитаксия осуществлялась в графитовом устройстве прокачного типа из ограниченного раствора-расплава $\mathrm{Ga}-\mathrm{As}$, процесс проводился в кварцевом реакторе в атмосфере водорода (проток 300 л/ч, точка росы $-80^{\circ} \mathrm{C}$ ). В качестве легирующих компонентов в исходный раствор-расплав добавлялись примеси $\mathrm{Ga}_{2} \mathrm{O}_{3}, \mathrm{SiO}_{2}$, соотношение которых определяло тип проводимости эпитаксиального слоя арсенида галлия и уровень легирования [8]. Так, для получения электронного типа проводимости требуется повышенное содержание в расплаве компонента $\mathrm{Ga}_{2} \mathrm{O}_{3}$ и наоборот. Структура $p-p^{+}$-типа содержала слабо легированный слой $p$-GaAs толщиной 110 мкм, а структура $n-n^{+}$-типа - слабо легированный слой $n$-GaAs толщиной 50 мкм. Также по этой технологии были изготовлены высоковольтные $p-i-n$-диоды со структурой $p^{+}-p(20-40$ мкм $)-i(20-50$ мкм $)-n(40-60$ мкм $)-n^{+}$.

Омические и барьерные контакты формировались электронно-лучевым испарением на вакуумной напылительной установке фирмы Angstrom Engineering. Омический контакт (Ti/ $\mathrm{Au}, 20 / 100 \mathrm{Hм})$ напылялся на тыль- 
ную сторону образца при комнатной температуре. Затем формировался контакт Шоттки напылением алюминия ( 150 нм) при комнатной температуре. Размер барьерных контактов составлял $3000 \times 3000$ мкм.

Вольт-фарадные характеристики (ВФХ) и адмиттансспектры регистрировались с помощью прецизионного LCR-измерителя E4980A (KeysightTechnologies, USA) в диапазоне частот 20Гц-2МГц. Для измерений методом нестационарной спектроскопии глубоких уровней (НЕСГУ) использовалась автоматизированная установка с рабочей частотой 400 кГц и возможностью автоподстройки измерительного моста по активной и емкостной компонентам проводимости исследуемых структур. Низкотемпературные измерения проводились в гелиевом транспортном дьюаре. Температура измерялась платиновым термометром сопротивления и регулировалась перемещением измерительной штанги с образцом относительно уровня жидкого гелия в транспортном дьюаре.

Измерение вольт-амперных характеристик (BAX) проводилось на установке Keithley Instruments 4200-SCS с применением термостатированной ячейки.

Концентрации свободных носителей заряда, определенные по данным ВФХ, составили $\sim 2 \cdot 10^{15} \mathrm{~cm}^{-3}$ для образца с электронным и $\sim(2-4) \cdot 10^{14} \mathrm{~cm}^{-3}$ для образца с дырочным типом проводимости при комнатной температуре.

Предварительные исследования показали, что в GaAsструктурах с электронным типом проводимости $\left(n-n^{+}\right)$ отсутствуют ГУ с концентрацией $>10^{13} \mathrm{~cm}^{-3}$. Вероятно, это связано с малой концентрацией комплексов $\mathrm{Si}-\mathrm{O}$, что требуется для получения арсенида галлия электронного типа. Поэтому все дальнейшие исследования были направлены на изучение $\mathrm{GaAs}$ структур с дырочным типом проводимости.

\section{3. Результаты и их обсуждение}

Методы емкостной спектроскопии, в частности адмиттанс-спектроскопия и НЕСГУ, являются наиболее информативными методами исследования электрически активных примесей и дефектов (ловушек) в полупроводниках. В основе метода адмиттанс-спектроскопии лежит регистрация перезарядки примеси (дефекта) под воздействием переменного напряжения относительно малой амплитуды $[9,10]$. В этом методе регистрируются частотные и температурные зависимости емкостной $(C)$ и активной $(G)$ компонент адмиттанса (комплексной проводимости) исследуемой диодной структуры. При наличии в запрещенной зоне полупроводника одного или нескольких глубоких уровней в адмиттанс-спектрах возникают особенности: ступеньки в зависимости $C(T)$ и пики в зависимости $G(T)$. Анализ температурных зависимостей адмиттанс-спектров позволяет оценить глубину залегания ГУ и сечение захвата носителей на них.

Адмиттанс-спектры структуры $p-p^{+}$, зарегистрированные при нулевом смещении на структуре, приведены
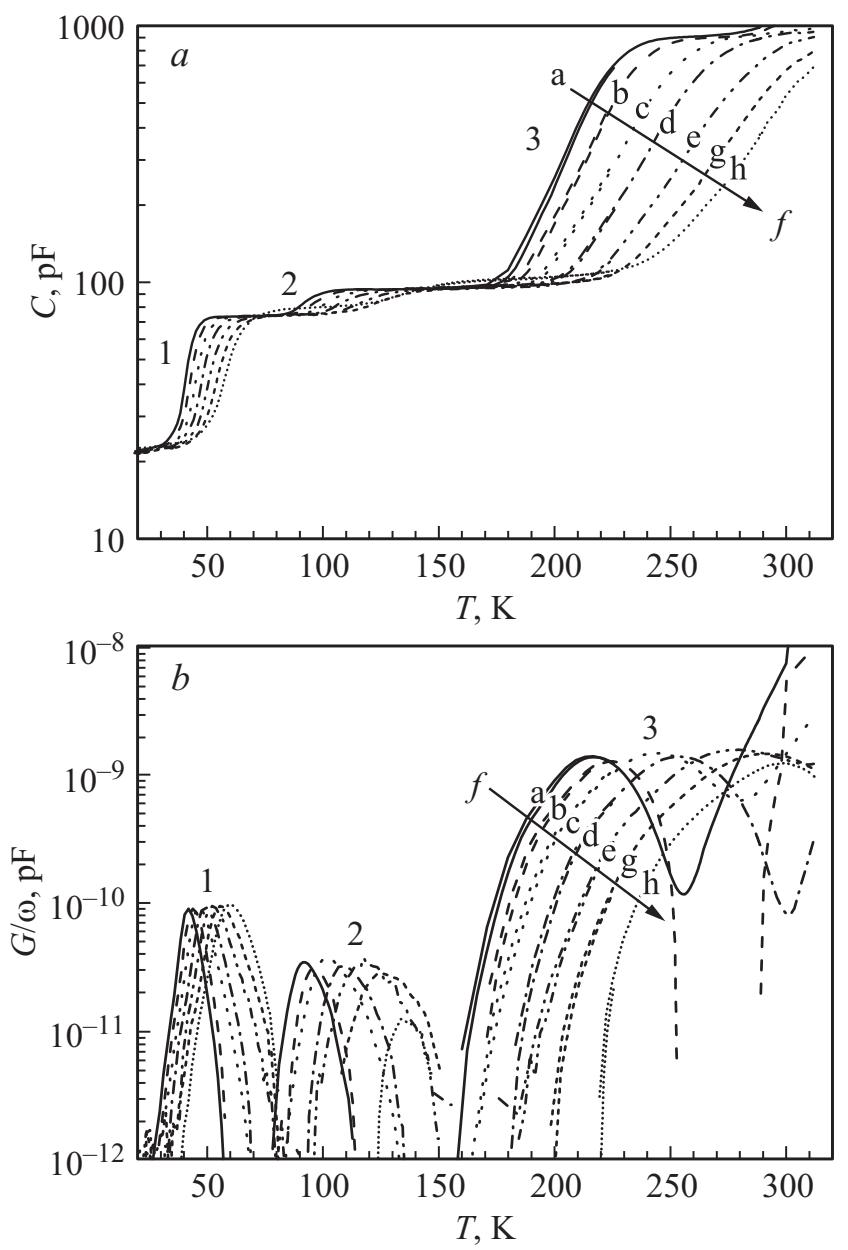

Рис. 1. Зависимость емкости $C(a)$ и высокочастотной проводимости $G(b)$ структуры $p-p^{+}$от температуры на разных частотах $f$, кГц: а $-2, \mathrm{~b}-6.3, \mathrm{c}-20, \mathrm{~d}-63$, е -200 , $\mathrm{g}-630, \mathrm{~h}-2000$.

на рис. $1, a, b-C(T)$ и $G(T) / \omega$. При сканировании температуры в диапазоне $T=20-320 \mathrm{~K}$ в зависимости $C(T)$ наблюдаются ступеньки, связанные с перезарядкой дырочных ловушек, а в спектрах проводимости наблюдаются максимумы. При увеличении частоты, на которой проводятся измерения адмиттанса, спектры $C(T)$ и $G(T) / \omega$ смещаются вверх по температуре. Пики 2 и 3 (рис. 1) мы связываем с перезарядкой ГУ, пик 1 - с вымораживанием основных носителей заряда, т.е. дырок. При увеличении температуры выше $300 \mathrm{~K}$ мы наблюдали рост емкости и проводимости, указывающие на ионизацию третьего ГУ с большей энергией ионизации. Однако выявить его в адмиттанс-спектрах не представляется возможным из-за роста постоянной составляющей проводимости при повышенных температурах и резкого уменьшения добротности диода.

В методе НЕСГУ (в отличие от адмиттанс-спектроскопии, которая имеет дело с равновесными значениями компонент адмиттанса) регистрируется временной от- 


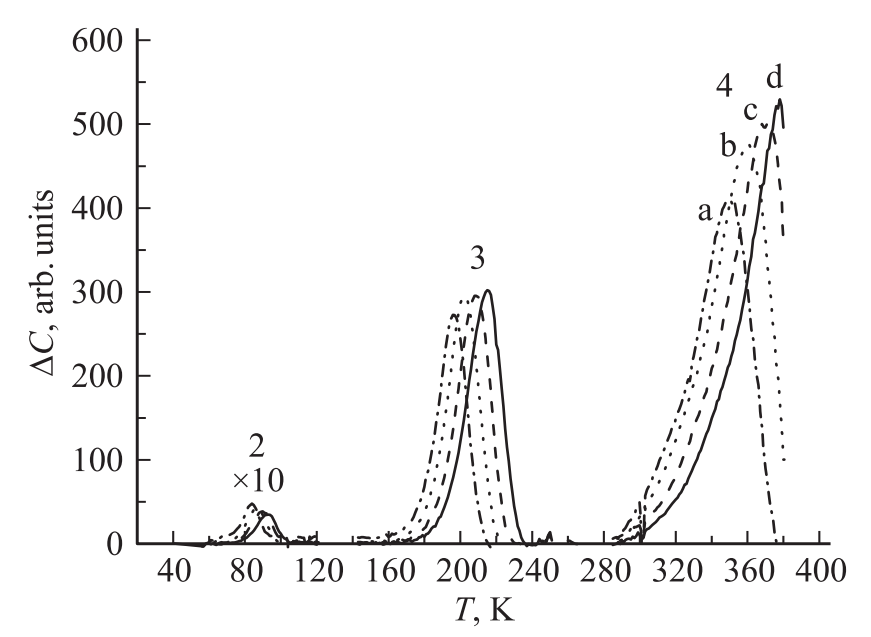

Рис. 2. Сигнал НЕСГУ $\Delta C p-p^{+}$-структуры при импульсе обеднения +12 В и импульсе заполнения $0 \mathrm{~B}$. Времена выборки $t_{1} / t_{2}$, мс: a $-0.2 / 0.4, \mathrm{~b}-0.4 / 0.8, \mathrm{c}-0.8 / 1.6, \mathrm{~d}-1.6 / 3.2$.

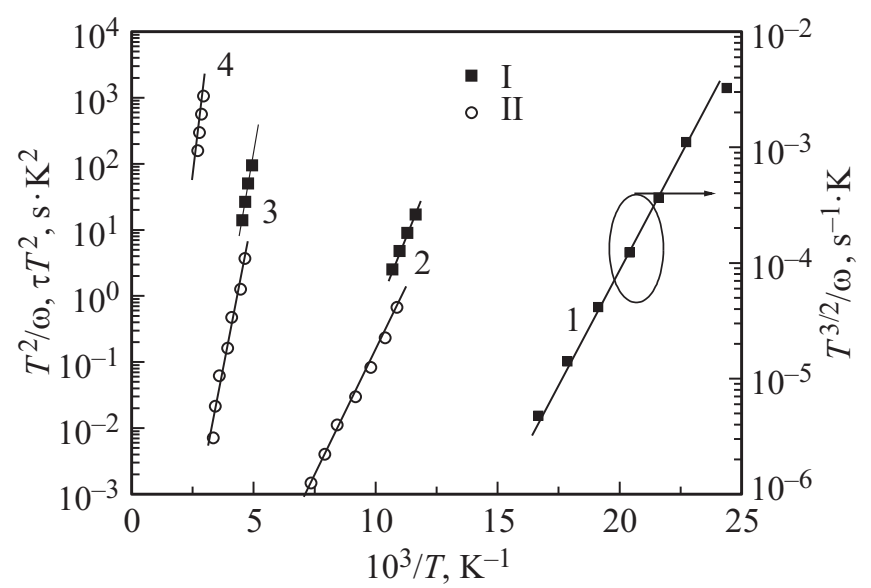

Рис. 3. Зависимости Аррениуса для дырочных ловушек в $p-p^{+}$-структуре (левая ось), определенные методиками адмиттанс-спектроскопии (I) и НЕСГУ (II) и зависимость для вымораживания носителей в $p-p^{+}$-структуре (правая ось), определенная методом адмиттанс-спектроскопии.

клик ГУ на резкое (ступенчатое) увеличение обратного смещения, прикладываемого к исследуемой структуре (к $p-n$-переходу или диоду Шоттки) [11]. По сравнению c адмиттанс-спектроскопией метод НЕСГУ обладает большей чувствительностью по отношению к примесям и дефектам с ГУ, но не позволяет регистрировать уровни (как правило, с малой энергией ионизации), определяющие тип проводимости полупроводника.

Спектр НЕСГУ GaAs-структуры $p-p^{+} \Delta C(T)$ в интервале температур $T=20-400 \mathrm{~K}$ приведен на рис. 2. Спектр содержит три уровня - пики 2, 3 и 4. Отношение времен выборки при записи спектров поддерживалось постоянным $t_{2} / t_{1}=2$. Пропорциональное увеличение времен выборки приводит к смещению спектра НЕСГУ вниз по температурной шкале. Обработка спектров НЕСГУ осуществлялась общепринятым методом [11].

На рис. 3 в координатах $T^{3 / 2} / \omega=F(1 / T)$ приведены результаты обработки данных адмиттанс-спектроскопии по наиболее низкотемпературному уровню 1 , регистрируемому в диапазоне температур $30-70 \mathrm{~K}$. Отметим, что возникновение пика зависимости $G(T)$ и ступеньки зависимости $C(T)$ обусловлено в данном случае вымораживанием носителей заряда на основной (мелкой) примеси в области электрической нейтральности измеряемого диода, которая определяет концентрацию дырок [12]. При определении энергии ионизации была учтена температурная зависимость эффективной плотности состояний в зоне проводимости $N_{C}(T) \propto T^{3 / 2}$, зависимость подвижности носителей заряда от температуры не учитывалась. Энергия ионизации этого уровня составила 0.074 эВ. Можно высказать предположение, что этот уровень близок к определенному в работе $[13,14]$ собственному двойному акцептору с энергией 78 мэВ. Авторы этой работы в результате комплексного исследования (эффект холла, НЕСГУ, фотолюминесценция, инфракрасное поглощение) $p$-GaAs, выращенного методом Чохральского из нестехиометрического расплава с дефицитом мышьяка, обнаружили два акцепторных уровня (с энергиями ионизации 78 и 203 мэВ), которые они приписали изолированному собственному антиструктурному дефекту $\mathrm{Ga}_{\mathrm{As}}$. В нашем случае процесс жидкофазной эпитаксии GaAs проводится из расплава галлия в режиме диффузии мышьяка к поверхности подложки. Соответственно могут возникать условия, когда мышьяка на границе роста не хватает (низкие температуры, большая скорость охлаждения т. е. ограничения для диффузии), поэтому возникновение дефекта типа Ga на месте As вполне вероятно. Повидимому, этот уровень обеспечивает дырочную проводимость структуры и поэтому в методе НЕСГУ он себя не проявляет.

На рис. 3 приведены зависимости Аррениуса для пиков 2, 3 и 4, построенные по данным НЕСГУ и адмиттанс-спектроскопии. Данные адмиттанс-спектроскопии обрабатывались в координатах $T^{2} / \omega=F(1 / T)$, данные НЕСГУ - в координатах $\tau T^{2}=F(1 / T)$. Здесь $\omega=2 \pi f, \tau=\left(t_{2}-t_{1}\right) / \ln \left(t_{2}-t_{1}\right), f-$ частота, на которой регистрировался адмиттанс-спектр, $t_{2}$ и $t_{1}-$ времена выборки при регистрации спектра НЕСГУ, $T$ температура, соответствующая центру спектральной линии в спектрах НЕСГУ или $G(T)$. Отметим, что спектр НЕСГУ наблюдается в области более низких температур по сравнению с адмиттанс-спектром. Это объясняется тем, что в НЕСГУ (в силу аппаратурных особенностей) мы работаем в области больших времен перезарядки ГУ (по сравнению с адмиттанс-спектроскопией), что требует более низких температур для регистрации соответствующей спектральной линии. Энергии активации уровней 2, 3 и 4, вычисленные из прямых Аррениуса на рис. 3 , составили $\sim 0.16, \sim 0.41$ и $\sim 0.7$ э; концентрации, определенные по данным НЕСГУ и вольт- 


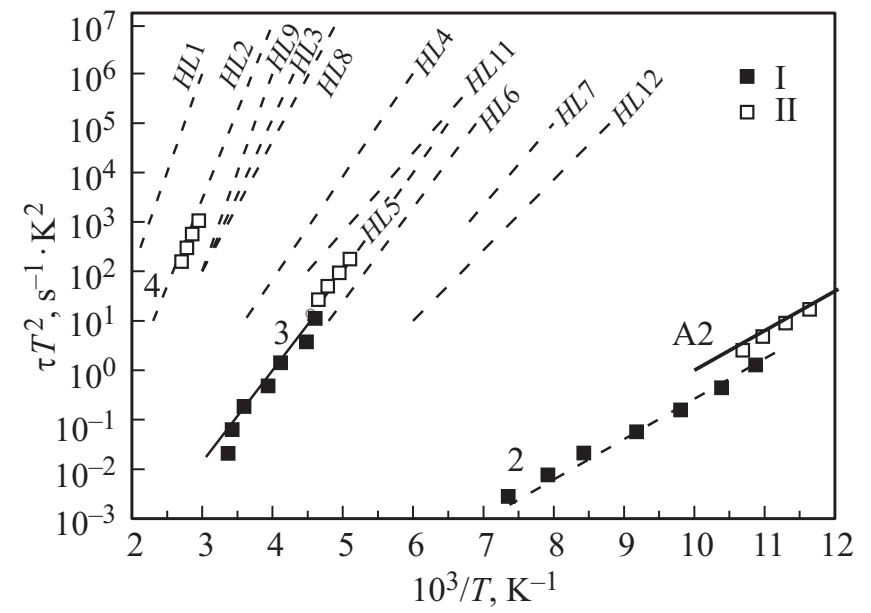

Рис. 4. Зависимости Аррениуса для дырочных ловушек в $p-p^{+}$-структуре, определенные методиками адмиттансспектроскопии с коррекцией (I) и НЕСГУ (II), и сигнатуры дырочных ловушек $H L 1-H L 12$ из каталога [16]. Прямая А2 взята из работы [13].

фарадного профилирования, равны $\sim 5 \cdot 10^{13}, \sim 2 \cdot 10^{14}$, $\sim 3 \cdot 10^{14} \mathrm{~cm}^{-3}$ соответственно.

Отметим, что для каждого из уровней наблюдается хорошее согласие энергий активации, определенных по данным НЕСГУ и адмиттанс-спектроскопии, что говорит о достоверности полученных результатов. Обращает на себя внимание тот факт, что для каждого из уровней зависимости Аррениуса, построенные по данным НЕСГУ и адмиттанс-спектроскопии, сдвинуты друг относительно друга по оси ординат. С нашей точки зрения, это обусловлено высокой концентрацией регистрируемых ГУ $\left(N_{T}\right)$ относительно концентрации носителей $p$. В [15] показано, что обработку данных адмиттансспектроскопии при концентрации $N_{T} / p>1$ следует выполнять с учетом того, что максимум пика $G(T)$ достигается при выполнении условия $\omega \tau=1+\left(N_{T} / p\right)\left(x_{T} / W\right)$, где $x_{T}$ - расстояние до точки пересечения уровня Ферми с ГУ, $W$ - толщина обедненной области. Тогда выражение для времени эмиссии дырок из ГУ в случае адмиттанс- спектроскопии примет вид

$$
\tau=\frac{1+\left(N_{T} / p\right)\left(x_{T} / W\right)}{\omega},
$$

и можно построить скорректированную зависимость $\tau T=F(1 / T)$ для данных адмиттанс-спектроскопии.

Учет поправок на большую концентрацию ГУ приводит к сближению зависимостей Аррениуса, построенных для обоих методов, что показано на рис. 4. Остающееся некоторое расхождение для уровня 2 можно объяснить большим последовательным сопротивлением образца при низкой температуре, которое может приводить к подобному сдвигу прямой Аррениуса [15].

На рис. 4 зависимости Аррениуса для ГУ, обнаруженных в исследованной нами GaAs-структуре $p-p^{+}$, сопоставляются с литературными данными. Уровень 2 с энергией активации $\sim 0.16$ эВ можно, так же как и уровень 1 , связать с упоминавшимся выше дефектом $\mathrm{Ga}_{\mathrm{As}}$, имеющим двухзарядовое состояние и второй уровень $E_{v}+203$ мэВ. Прямая Аррениуса, взятая из работы [14] (прямая A2), практически накладывается на наши экспериментальные точки НЕСГУ и дает энергию 0.15 эВ. Однако более детальные измерения, проведенные авторами по методике D-DLTS, которая позволяет определять профили ГУ и полевую зависимость энергии ионизации центров, показали, что его энергия с учетом эффекта Пула-Френкеля составляет 0.203 эВ.

Зависимости Аррениуса для ГУ 3 и 4 с энергиями активации $\sim 0.41$ и $\sim 0.7$ эВ близки к зависимостям Аррениуса, приводимым в обзорах и справочниках [16] для центров $H L 5$ и $H L 2$ соответственно. В литературе отмечается, что эти центры характерны для слабо легированных слоев GaAs, выращенных методом ЖФЭ в атмосфере водорода [7]. Предполагается, что за их формирование ответственны атомы кремния и комплексы $\mathrm{Si}-\mathrm{O}[1]$.

Были исследованы высоковольнные $p-i-n$-диоды, выращенные по этой же технологии. Измерялись ВАХ $I(V)$ в диапазоне температур $250-400 \mathrm{~K}$. Показано, что при напряжениях до нескольких десятков вольт $\lg (I) \propto V^{1 / 2}$, т. е. ток растет пропорционально толщине области пространственного заряда, из чего можно сделать вывод, что обратный ток в диодах определяется генерационнорекобинационным механизом. В этом случае энергия активации, извлеченная из температурной зависимости BAX, будет определять глубину залегания генерационно-рекобинационного центра относительно одной из зон [17].

Были построены зависимости Аррениуса для различных диодных структур (рис. 5), которые достаточно хорошо описываются прямыми линиями. Вычисленные энергии активации имеют близкие к ранее определен-

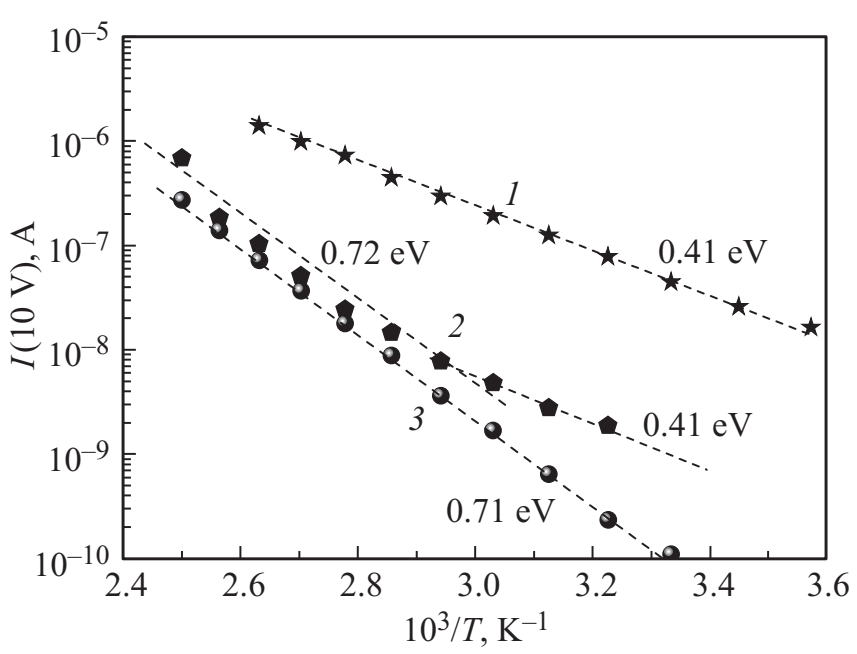

Рис. 5. Температурные зависимости обратных токов $p-i-n$ диодов, изготовленных методом ЖФЭ, в координатах Арpениуса. Образцы: 1 - \#3255, 2 - \#737, 3 - \#0109. 
ным емкостными методами значения: 0.41 эВ (HL5) и 0.72 эВ $(H L 2)$. При этом обратные токи $p-i-n$-диодов определяются соотношением их концентраций. Так, из рисунка видно, что в зависимости от условий роста доминирующими могут быть либо HL5 - структура \#3255, либо HL2 - структура \#0109. Когда концентрации центров сравнимы, то в разных температурных диапазонах зависимости Аррениуса проявляют себя оба центра - структура \#737.

\section{4. Заключение}

Выполненные емкостные исследования показали, что в GaAs-структурах с электронным типом проводимости $\left(n-n^{+}\right)$отсутствуют глубокие уровни с концентрацией $>10^{13} \mathrm{~cm}^{-3}$. B GaAs-структурах с дырочным типом проводимости $p-p^{+}$обнаружены три глубоких акцепторных уровня с энергиями активации $\sim 0.7, \sim 0.41$ и $\sim 0.16$ эВ. Первые два уровня известны как $H L 2$ и $H L 5$, связываются с особенностями роста слоев $\mathrm{GaAs}$ в методе ЖФЭ и являются эффективными рекомбинационными центрами, определяющими обратные токи и времена жизни носителей в $p-i-n$-диодах.

Сравнение с литературными данными показывает, что уровень с меньшей энергией активации, $E_{v}+0.16$ эВ, может быть связан с двухзарядным акцепторным уровнем собственного антиструктурного дефекта GaAs в состоянии $(-/--)$, который с большой долей вероятности может присутствовать при выращивании методом ЖФЭ. Вымораживание дырок, наблюдаемое в $p-p^{+}$-диоде при температурах ниже $50 \mathrm{~K}$, связано с этим же уровнем $\mathrm{Ga}_{\mathrm{As}}$ в зарядовом состоянии $(0 /-)$. Энергия активации его составляет 0.074 эВ, и он является примесным уровнем, определяющим тип проводимости полупроводника.

Анализ температурных зависимостей обратных ВАХ $p-i-n$-диодов подтверждает существование в них генерационно-рекомбинационных центров, подобных по параметрам HL2 и $H L 5$.

Работа поддержана программами президиума РАН. В работе использовано оборудование ЦКП ИФМ РАН „Физика и технология микро- и наноструктур“.

\section{Список литературы}

[1] В. Войтович, А. Думаневич, А. Гордеев. Современная электроника, 6, 10 (2014).

[2] S. Bellone, G. Cocorullo, F.G. Della Corte, H.L. Hartnageland, G. Schweeger. Sol. St. Electron., 35 (6), 821 (1992).

[3] М.М. Соболев, П.Р. Брунков, С.Г. Конников, М.Н. Степанова, В.Г. Никитин, В.П. Улин, А.Ш. Долбая, Т.Д. Камушадзе, Р. Майсурадзе. ФТП, 25 (6), 1058 (1989).

[4] П.Н. Брунков, С. Гайбуллаев, С.Г. Конников, В.Г. Никитин, М.И. Папенцев, М.М. Соболев. ФТП, 25 (1), 338 (1991).

[5] Л.С. Берман, В.Г. Данильченко, В.И. Корольков, Ф.Ю. Солдатенков. ФТП, 34 (5), 558 (2000).
[6] O. Korolkov, J. Toompuu, T. Rang. Elrektronika Elektrotechnika (Elrektronics and Electrical Engineering), 19 (10), 1392 (2013).

[7] Я. Тоомпуу, О. Корольков, Н. Слепчук, Т. Ранг. Электроника и электротехника. Каунас: Технология, 4, 51 (2010).

[8] В.Л. Крюков, Е.В. Крюков, Л.А. Меерович, С.С. Стрельченко, К.А. Титивкин. Патент RU 2488911 C1. Заявка № 2012110151/28 от 19.03.2012.

[9] D.L. Losee. J. Appl. Phys., 46, 2204 (1975).

[10] J.L. Pautrat, B. Katirciogli, N. Magnea, D. Bensahel, J.C. Pfistert, L. Revioil. Sol. St. Electron., 23, 1159 (1980).

[11] D.V. Lang. J. Appl. Phys., 45, 3023 (1974).

[12] Л.С. Берман, А.А. Лебедев. Емкостная спектроскопия глубоких центров в полупроводниках (Л., Наука, 1981).

[13] G. Roos, A. Schoner, G. Pencl, K. Krambrock, B.K. Meyer. Mater. Sci. Forum, 38-41, 951 (1989).

[14] Phil Won Yu, W.C. Mitchel, M.G. Mier, S.S. Li, W.L. Wang. Appl. Phys. Lett., 41, 532 (1982).

[15] S.R. Forrest, O.K. Kim. J. Appl. Phys., 53, 5738 (1982).

[16] A. Dargis, J. Kundrotas. Handbook on physical properties of Ge, Si, GaAs and InP (Vilnus, 1994).

[17] A. Czerwinski, E. Simoen, A. Poyai, C. Claeys. J. Appl. Phys., 94, 1218 (2003).

Редактор Л.В. Шаронова

\section{Capacitance spectroscopy of hole traps in high-resistance structures of gallium arsenide grown by liquid-phase method}

A.V. Murel ${ }^{1}$, V.B. Shmagin ${ }^{1}$, V.L. Krukov' ${ }^{2}$, S.S. Strelchenko ${ }^{2}$, E.A. Surovegina ${ }^{1}$, V.I. Shashkin ${ }^{1}$

${ }^{1}$ Institute for Physics of Microstructures,

Russian Academy of Sciences, 603087 Nizhny Novgorod, Russia

$2 \mathrm{OOO}$ „MeGa Epitech“,

248033 Kaluga, Russia

Abstract Hole conductivity GaAs structures grown by liquidphase epitaxy were studied by the capacitance spectroscopy technique. Three deep acceptor levels with activation energies of $\sim 0.7,0.41$ and $0.16 \mathrm{eV}$ were discovered. The first two levels known as $H L 2, H L 5$ are associated with the features of growth process. They are effective recombination centers determining the reverse current in $p-i-n$ diodes. It was proven by the study of reverse current temperature dependences. The latter level with the energy $E_{v}+0.16 \mathrm{eV}$ may be associated with the double acceptor level of intrinsic antisite defect in GaAs, which also determines the doping level in singly charged state. 